\title{
Ketamine as a Novel Psychopharmacotherapy for Eating Disor- ders: Evidence and Future Directions
}

\author{
Anya Ragnhildstveit 1,2,*, Matthew Slayton 1,2, Laura Kate Jackson 2,3, Madeline Brendle ${ }^{3,4}$, Sachin Ahuja ${ }^{3}$, Willis \\ Holle ${ }^{2}$, Claire Moore ${ }^{3}$, Kellie Sollars ${ }^{3}$ Paul Seli ${ }^{1}$ and Reid Robison ${ }^{3,5}$ \\ 1 Department of Psychology and Neuroscience, Duke University, Durham, North Carolina, United States; \\ anya.ragnhildstveit@duke.edu (A.R.); matthew.slayton@duke.edu (M.S.); paul.seli@duke.edu (P.S.) \\ 2 Integrated Research Literacy Group, Draper, Utah, United States; anya.ragnhildstveit@irlg.org (A.R.); mat- \\ thew.slayton@irlg.org (M.S.); laura.jackson@irlg.org (L.K.J.); willis.holle@irlg.org (W.H.) \\ 3 Novamind, Draper, Utah, United States; ljackson@cedarpsychiatry.com (L.K.J.); mbrendle@cedarclinicalre- \\ search.com (M.B.); sachin@novamind.ca (S.A.); claire@novamind.ca (C.M.); ksollars@cedarpsychiatry.com \\ (K.S.); reid@novamind.ca (R.R.) \\ 4 Department of Pharmacotherapy, University of Utah College of Pharmacy, Salt Lake City, Utah, United \\ States; madeline.brendle@utah.edu (M.B.) \\ 5 Department of Psychiatry, University of Utah School of Medicine, Salt Lake City, Utah, United States; \\ reid.robison@hsc.utah.edu (R.R.) \\ * Correspondence: anya.ragnhildstveit@duke.edu; Tel.: +1 (801) 448-3331 (A.R.)
}

\begin{abstract}
Eating disorders (EDs) are serious, life-threatening psychiatric conditions associated with physical and psychosocial impairments, as well as high morbidity and mortality. Given the chronic refractory nature of EDs and the paucity of evidence-based treatments, there is a pressing need to identify novel approaches for this population. The noncompetitive N-methyl-D-aspartate receptor (NMDAr) antagonist, ketamine, has recently been approved for treatment-resistant depression, which exhibits rapid and robust antidepressant effects, particularly among clinical non-responders. It is now being investigated for several new indications, including obsessive-compulsive, post-traumatic, and substance use disorder; and shows transdiagnostic potential for EDs. As such, the aim of this review is to examine contemporary findings on the treatment of EDs with ketamine, whether used as a primary, adjunctive, or combination pharmacotherapy. Avenues for future research are also discussed. Overall, results are encouraging and point to therapeutic value, yet are limited to case series and reports principally on anorexia nervosa. Further empirical work is thus needed to explore and establish ketamine efficacy for EDs, and to inform targeted treatment strategies.
\end{abstract}

Keywords: esketamine; ketamine; ketamine assisted psychotherapy; eating disorder; anorexia nervosa; bulimia nervosa; binge eating disorder; pharmacology; psychedelics; treatment

\section{Introduction}

Eating disorders (EDs) are highly prevalent, disabling, and potentially fatal psychiatric illnesses characterized by abnormal eating and weight disturbances [1,2]. They are etiologically complex and multifactorial in nature, often leading to severe psychological and somatic complications [3-6], marked functional impairments [7-9], and poor quality of life and overall prognosis [10-12]. The socioeconomic burden of EDs in the United States is estimated at $\$ 64.7$ billion annually, equating to $\$ 11,808$ per individual diagnosed [13]. Non-financial, yet significant, reductions in personal well-being are further valued at $\$ 326.5$ billion [13]. Approximately $8-15 \%$ of children and adolescents $[3,14]$ and $16 \%$ of adults [15] are affected by EDs, with weighted population means of lifetime prevalence at $1.6 \%$ for anorexia nervosa (AN: $1.4 \%$ women, $0.2 \%$ men), $2.5 \%$ for bulimia nervosa (BN: $1.9 \%$ women, $0.6 \%$ men), $3.8 \%$ for binge eating disorder (BED: $2.8 \%$ women, $1.0 \%$ men), and $7.9 \%$ for eating disorder not otherwise specified (EDNOS: $4.3 \%$ women, $3.6 \%$ men) [16]. However, the prevalence of EDs is greatly underestimated, primarily due to variable diagnostic classifications, underreporting, and lack of research funding [17]. Moreover, 
EDs are associated with significantly elevated morbidity and mortality compared to the general population [18,19], with the highest rates occurring in AN (standardized mortality ratio $[S M R]=5.9-10.5)[20,21]$. Anorexia nervosa, in particular, carries a 12-fold increased risk of death - higher than any other psychological condition-to which low body mass index, poor social adjustment, and alcohol dependence have been reported as significant predictors [22]. Mortality rates for EDs are further complicated by concomitant psychiatric comorbidities (e.g., anxiety, depression, and substance abuse) as well as symptom persistence (> 12 months).

While various models have attempted to explain ED pathogenesis, the mechanisms subserving disease onset, progression, and maintenance remain not fully understood [23]. Notwithstanding, several hypotheses surround the neurobiology of EDs, which is supported by a growing body of literature (reviewed in Frank et al. [24] and Finch et al. [25]). Studies over the past decade have predominantly focused on correlating dimensions of ED pathology with structural brain changes, specifically in grey matter volume (GMV) and cortical thickness (CT). Evidence suggests that restrained eating is associated with aberrant activity in a complex network of regions implicated in emotional, self-related, and visuospatial processing; and is linked to increased GMV in the parietal lobule, precuneus, and parahippocampal, temporal, and frontal gyri [25]. These areas play a fundamental role in regulating affect, interpreting social information, and integrating spatial cues. Impairments may consequently reinforce restrictive cognitions and behaviors, in addition to body image distortions, present in AN. Comparatively, disinhibited eating is associated with altered activation in regions implicated in reward, emotional, and motivational processing; and is linked to increased GMV in the orbitofrontal gyrus, an area responsible for encoding value representations of food, as well as decreased GMV in the cingulate cortex, an area critical for regulating affect and goal-directed behavior [25]. Hyperactive rewardand hedonic-based responses to food may therefore drive overconsumption present in BN and BED. Evidence on CT, however, is heterogeneous across ED studies, with varying reports of high or low CT that either persists or normalizes after recovery [26]. This discrepancy may in part arise from variation in neuroimaging and analytic techniques, suggesting that standard approaches are needed to reliably define ED pathophysiology and subgroups $[27,28]$. Studies have further investigated functional brain changes in EDs, identifying several intrinsic connectivity networks that may underlie and perpetuate maladaptive eating, including the executive control network (ECN) [29-35], default mode network (DMN) [30,35-38], reward network (RN) [29,39-43], and salience network (SN) $[35,44-46]$. These circuits are involved in goal-directed attention and cognitive flexibility, mentalizing and interoception, reward processing and sensitivity, and salient stimuli detection, respectively. As such, impairments may perturb adaptive eating behavior and body perception, as well as food reward valuation and readiness. Yet data remains limited by number of available studies, small sample sizes, and inconsistent methodology; and should be considered with caution. Evidence on functional network involvement beyond $\mathrm{AN}$ and $\mathrm{BN}$ is additionally lacking [47].

Currently, the primary care pathway for EDs is psychotherapy and nutritional counseling followed by psychotropic medication [48]. Treatment is generally provided on an outpatient basis, with medically compromised individuals recommended to higher levels of ED care, including intensive outpatient, partial hospitalization, and residential programs [49,50]. For BN [51,52] and BED [53], cognitive behavioral therapy (CBT, transdiagnostic) remains the most effective psychological treatment in managing ED symptomatology; however, such efficacy is not established for AN [54]. Other evidence-based modalities shown to yield clinical benefit for EDs include focal psychodynamic therapy (FPT, psychodynamic) [55,56], specialist supportive clinical management (SSCM, atheoretical) [57-59], and the Maudsley model of anorexia nervosa treatment for adults (MANTRA, cognitive-interpersonal) [59,60]. Family-based treatment (FBT, atheoretical) is particularly effective for children and adolescents [61-63]. In regard to second-line pharmacotherapies for EDs, drug classes comprise antidepressants (e.g., fluoxetine, citalopram, fluvoxamine, 
and sertraline), antiepileptics (e.g., carbamazepine and topiramate), opioid antagonists (e.g., naltrexone, naloxone, and nalmefene), and neurostimulants (e.g., lisdexamfetamine), among others. These psychotropics are principally used to treat BN [64-66] and BED $[64,66,67]$, showing modest improvements in impulse control (i.e., regulation of binge eating and purging), cognitive distortions (e.g., dichotomous thinking and catastrophizing), and concomitant psychiatric comorbidities (e.g., anxiety and depression). Despite no approved pharmacological agents available for AN, atypical antipsychotics-namely olanzapine [68,69] and aripiprazole [70] - have been used to augment weight gain and reduce ritualistic tendencies around food. Though, clinical management of $A N$, by and large, remains difficult, with limited and discouraging data supporting psychotherapeutic approaches [71] as well as medication trials [72]. Poor management of AN is reflected by disease chronicity and low remission rates [73].

Relatedly, three studies evaluating long-term trajectories of EDs found that $64 \%$ of patients with $\mathrm{AN}(N=1,693)$ [74], 53\% of patients with $\mathrm{BN}(N=2,033)$ [75], and $30 \%$ of patients with BED $(N=68)$ [76] met full diagnostic criteria for an ED at 10-20 years followup. Outcome predictors included symptom severity (AN), illness duration (AN), psychiatric comorbidity (BN, BED), treatment age (BN), follow-up length (AN, BN), global functioning $(B N)$, body dissatisfaction (BED), drive for thinness (BN), impulsivity (BED), sexual abuse (BED), and self-injury (BN), respectively. More than 50 years of literature on EDs further suggests that less than half of sufferers achieve full remission, a third experience residual symptoms, and a fifth become chronically ill [77-79]. Individuals with repeat treatment failures over protracted periods are considered to have severe and enduring EDs, with active disease cut-off points typically set at seven years in duration [80,81]. However, thresholds for severe and enduring EDs vary between studies (e.g., 5-10 years) due to the lack of an empirically-derived and -accepted definition in the field [80,82]. "Both the clinician and [chronically ill] patient often share the experience of hopelessness and despair about the likelihood of meaningful change." [83] Given the chronic refractory nature, increased risk of premature death, and paucity of high-quality, evidence-based treatments associated with severe and enduring EDs, pragmatic shifts toward harm reduction, palliative care, and quality of life over recovery have been proposed for this subgroup $[58,80,83,83-87]$. This stems from efforts to minimize adverse impacts on sufferers and their caregivers and external support systems, as well as society at large $[73,88]$.

Ketamine, an N-methyl-D-aspartate receptor (NMDAr) antagonist, is a dissociative anesthetic used for diagnostic and surgical procedures, in addition to peri- and post-operative pain management $[89,90]$. It was developed in the 1960's as a fast-acting alternative to phencyclidine (PCP) [91], and is a 1:1 racemic mixture of its two optic enantiomers: $S(+)-$ ketamine (esketamine) and R(-)-ketamine (arketamine) [92,93]. Comparatively, S(+)-ketamine has a 3-4 fold higher binding affinity for the NMDA receptor than R(-)-ketamine [94], and carries stronger anesthetic and analgesic potency [95-97]. Ketamine is further known to produce psychotomimetic and psychodysleptic side effects (e.g., depersonalization and derealization) as well as ephemeral increases in glutamate release, with positive downstream effects on synaptogenesis and neuroplasticity [98]. In 2000, the first double-blind, placebo-controlled trial of ketamine in depressed patients revealed that subanesthetic doses ( $0.5 \mathrm{mg} / \mathrm{kg}$ infused over 40 minutes) had rapid and robust antidepressant effects [99]. Numerous studies have since replicated this finding [100-104], with metaanalyses showing acute and prolonged antidepressant efficacy of both single and repeated ketamine administration [105-108]. This eventually led to the approval of intranasal esketamine (Spravato ${ }^{\circledR}$ ) for treatment-resistant depression by the Food and Drug Administration (FDA) in 2019 [109,110]. Recently, ketamine has been investigated for several new indications [111,112], including obsessive-compulsive [113], post-traumatic [114,115], and substance use $[113,116]$ disorder. The interest in using ketamine in EDs originates from (a) its capacity to reduce cognitive and behavioral symptoms among psychiatric non-responders; and (b) the pressing need to identify treatment alternatives for EDs, of which 
are increasingly prevalent [16], have yet to benefit from pharmacological progress [64], and remain a leading public health concern [12].

\section{Use of Ketamine in Eating Disorders}

To date, few studies have examined the therapeutic use of ketamine for EDs, which are limited to case series [117,118] and reports [119-121] (Table 1); and are focused on AN over other primary (BN and BED) and secondary (pica, RD, and ARFID) subgroups. Mills et al. first introduced the dissociative anesthetic as a novel treatment for compulsive EDs in 1998, where 15 patients with atypical, chronic refractory AN of 11.3 years \pm 5.0 were treated with intermittent ketamine infusions combined with oral nalmefene, an opiate receptor antagonist [117]. Specifically, AN presentation consisted of no comorbidity $(n=5)$, BN comorbidity $(n=2)$, OCD comorbidity $(n=5), \mathrm{BN}$ and OCD multi-comorbidity $(n=1)$, and BN and AUD multi-comorbidity $(n=2)$. Patients received $2-15$ ketamine infusions scheduled at 5-21-day intervals, depending on clinical response, that were delivered at 20 $\mathrm{mg} /$ hour over 10 hours. This was a fairly intense drug regimen - relative to current studies on ketamine and mental health [122] - previously used to treat post-operative pain [123] and acute war injuries [124]. Marked and sustained remission were observed in responders $(n=9)$ compared to non-responders $(n=6)$, with no-to-minimal disease activity at 7 24 months follow-up. Moreover, responders showed significant reductions in obsessivecompulsive neurosis $(p<.001)$, in addition to increased weight acceptance, partial-to-complete weight restoration, and resolved amenorrhoea. No significant improvements were reported for non-responders. Investigators attributed this result to premature relapses following treatment, during which compulsive drives may have been reestablished, and/or the result of insufficient doses of nalmefene. Overall, clinical response $(\geq 50 \%$ reduction in symptom severity) was associated with AN subtype (-R, restricting; $-\mathrm{BP}$, binge/purge).

A recent longitudinal case series similarly produced positive outcomes, showing repeat dosing of ketamine to be moderately effective in four patients diagnosed with severe and enduring AN-R $(n=2)$ or EDNOS-BP $(n=2)$ and comorbid TRD of 11.0 years \pm 1.4 [118]. Patients had previously completed partial hospitalization programs for their ED, reported persistent negative affectivity, and failed several trials of monotherapy antidepressants of adequate dose and duration. Ketamine was administered intramuscularly and/or intravenously at $0.5 \mathrm{mg} / \mathrm{kg}$ over 30-90 minutes, with subsequent doses titrated to $0.8-0.9 \mathrm{mg} / \mathrm{kg}$ depending on treatment toleration and response. Repeat dosing was scheduled at 4-6-week intervals spanning $12+$ months, resulting in clinically meaningful changes in depression as well as modest changes in anxiety and disordered eating. Interestingly, patients with AN-R demonstrated robust and sustained responses compared to their EDNOS-BP counterparts, in addition to marked improvements in psychosocial functioning and quality of life trajectories. The differential degree of ketamine efficacy between ED subgroups merits further investigation.

Three case studies have also evaluated the effect of ketamine on ED symptomatology. Scolnick et al. published the first report of clinical remission in a 29-year-old woman with severe and enduring AN-R of 15 years, plus major depression and intermittent alcohol dependence, following repeated ketamine infusions adjunct to a ketogenic diet [119]. After adopting the high-fat, low-carbohydrate regimen for three months, the patient received four ketamine infusions starting at $0.75 \mathrm{mg} / \mathrm{kg}$ over 45 minutes, which were titrated to $1.0 \mathrm{mg} / \mathrm{kg}, 1.1 \mathrm{mg} / \mathrm{kg}$, and $1.2 \mathrm{mg} / \mathrm{kg}$ for each subsequent dosing, respectively. Ketamine infusions spanned 14 days at unspecified intervals, and were preceded by $4 \mathrm{~g}$ of sublingual ondansetron, a commonly used antiemetic, to prevent ketamine-associated nausea and vomiting. After the fourth dosing, the patient showed significant reductions in EDrelated obsessive-compulsive tendencies and depression, with accompanying weight restoration. This led to complete and sustained recovery of cognitive and behavioral symptoms for six months post-treatment. The adjunctive therapy was also useful for managing her periodic alcohol dependence. Considering data that suggests metabolic dysregulation 
underlies and accelerates AN etio-pathogenesis [125-127], the investigators queried whether the increase in ketone body production primed the response to ketamine.

Another case of severe and enduring AN complicated by major depression showed initial, but not sustained, response to ketamine treatment [120]. The 29-year-old female presented with chronic refractory AN-R and comorbid MDD of 11+ years, with persistent borderline and narcissistic personality features, as well active suicidality. Having failed several monotherapy and polytherapy medications, including standard and atypical antidepressants and antipsychotics, in addition to bilateral electroconvulsive therapy (ECT), the patient underwent nine ketamine infusions. Dosing was administered at $0.5 \mathrm{mg} / \mathrm{kg}$ over 40 minutes scheduled twice weekly for 4 weeks, excluding the ninth infusion that occurred in isolation. Following infusion three, the patient progressed from active to passive suicidal ideation, experiencing complete remission after infusion eight. However, the response to ketamine rapidly diminished, resulting in acute relapse of suicidality following infusion nine. While treatment efficacy was limited by ketamine's short duration of effect, initial symptom improvement was significant and achieved faster than with prior ECT. Most recently, Ragnhildstveit et al. evaluated the use of ketamine assisted psychotherapy (KAP) in treating a 21-year-old woman with extreme and enduring BN-BP of nine years [121]. This was the first ED report to administer ketamine with a psychotherapeutic component, and additionally for an 'extreme' BN severity specifier, according to DSM-5 criterion ( $\geq 14$ episodes/week) [128]. Upon clinic admission, the patient reported bingeeating and purging by self-induced vomiting 40 times daily, despite care at the outpatient, inpatient, and residential level. In the patient's final attempt at recovery, she underwent three courses of repeated KAP, with each course consisting of six sessions scheduled twice weekly at 48 -hour intervals ( 18 sessions total). KAP sessions comprised 30 minutes of preparatory psychotherapy, 40 minutes of intravenous ketamine $(0.5 \mathrm{mg} / \mathrm{kg})$ combined with guided psychotherapy, and 30 minutes of integration psychotherapy. A client-centered, humanistic approach to therapy was specifically leveraged to facilitate the process of selfactualization and behavior change. The patient progressively reduced her ED complaints and psychopathology over the treatment period, achieving complete cessation at three months post-treatment that sustained for over one year; an unexpected yet remarkable outcome given her initial chronic refractory state and extreme presentation.

Table 1. Characteristics and outcomes of studies using ketamine to treat eating disorders.

\begin{tabular}{|c|c|c|c|c|c|}
\hline Study [Ref] & Design & $\begin{array}{c}\text { Sample, Age/Mean } \\
\text { Age }\end{array}$ & Diagnosis & Drug Regimen & Outcome \\
\hline Dechant et al. [120] & Case study & $N=1,29$ & AN-R + MDD & $\begin{array}{c}\text { IV ketamine, } 9 \times 0.5 \mathrm{mg} / \mathrm{kg} \text { over } 40 \\
\mathrm{~min}\end{array}$ & $\begin{array}{l}\text { Partial remission: depression } \\
\text { and suicidality }\end{array}$ \\
\hline Mills et al. [117] & Case series & $\begin{array}{l}N=15,33.3 \\
\text { years } \pm 6.5\end{array}$ & AN-R, AN-BP & $\begin{array}{c}\text { IV ketamine, } 2-15 \times 20 \mathrm{mg} / \mathrm{h} \text { over } 10 \\
\mathrm{~h}\end{array}$ & $\begin{array}{l}\text { Partial remission: depression } \\
\text { and OCD-related ED symp- } \\
\text { toms }\end{array}$ \\
\hline $\begin{array}{c}\text { Ragnhildstveit et } \\
\text { al. [121] }\end{array}$ & Case study & $N=1,21$ & $\mathrm{BN}-\mathrm{BP}$ & $\begin{array}{c}\text { IV ketamine, } 18 \times 0.5 \mathrm{mg} / \mathrm{kg} \text { over } 40 \\
\mathrm{~min}\end{array}$ & $\begin{array}{l}\text { Complete and sustained remis- } \\
\text { sion: ED symptoms }\end{array}$ \\
\hline $\begin{array}{c}\text { Schwartz et al. } \\
{[118]}\end{array}$ & Case series & $\begin{array}{l}N=4,36.8 \\
\text { years } \pm 8.4\end{array}$ & $\begin{array}{l}\text { AN-R + TRD, ED- } \\
\text { NOS-BP + TRD }\end{array}$ & $\begin{array}{l}\text { IV/IM ketamine, } 5-9 \times 0.5 \mathrm{mg} / \mathrm{kg} \mathrm{ti}- \\
\text { trated to } 0.9 \mathrm{mg} / \mathrm{kg} \text { over } 30-90 \mathrm{~min}\end{array}$ & $\begin{array}{l}\text { Partial remission: depression, } \\
\text { anxiety, and ED symptoms }\end{array}$ \\
\hline Scolnick et al. [119] & Case study & $N=1,29$ & AN-R + MDD & $\begin{array}{l}\text { IV ketamine, } 4 \times 0.75 \mathrm{mg} / \mathrm{kg} \text { titrated } \\
\text { to } 1.2 \mathrm{mg} / \mathrm{kg} \text { over } 45 \mathrm{~min}\end{array}$ & $\begin{array}{l}\text { Complete and sustained remis- } \\
\text { sion: depression and OCD-re- } \\
\text { lated ED symptoms }\end{array}$ \\
\hline
\end{tabular}

*Notes: $\mathrm{ED}$ = eating disorder, $\mathrm{AN}-\mathrm{R}$ = anorexia nervosa restricting subtype, $\mathrm{AN}-\mathrm{BP}=$ anorexia nervosa binge/purge subtype, $\mathrm{BN}-\mathrm{BP}=$ bulimia nervosa binge/purge subtype, EDNOS-BP = eating disorder not otherwise specified binge/purge subtype, $\mathrm{MDD}=$ major depressive disorder, $\mathrm{TRD}=$ treatment-resistant depression, $\mathrm{OCD}=$ obsessive-compulsive disorder, IV = intravenous and IM = intramuscular. 


\section{Future Perspectives and Directions}

Over the past two decades, ketamine has emerged as a novel treatment for refractory depression, exerting rapid (e.g., $2-24 \mathrm{~h}$ ) and robust (e.g., $d=0.9-1.2$ ) antidepressant properties $[129,130]$. Interest in transdiagnostic applications has since grown, with more than 140 clinical trials in the National Institute of Health database (ClinicalTrials.gov) registered to investigate ketamine's therapeutic potential, comprising major depression (98; $70 \%)$, suicidal ideation $(21 ; 15 \%)$, post-traumatic stress disorder $(7 ; 5 \%)$, obsessive compulsive disorder $(5 ; 3.6 \%)$, autism spectrum disorder $(2 ; 1.4 \%)$, generalized anxiety disorder $(1 ; 0.7 \%)$, borderline personality disorder $(1 ; 0.7 \%)$, cognitive impairment $(1 ; 0.7 \%)$ and schizophrenia $(1 ; 0.7 \%)$ [111]. While data concerning ketamine and EDs is preliminary and principally limited to AN [117-121], results are nonetheless encouraging. A recent mixedmethods study $(N=200)$, examining patient attitudes towards complementary and emerging treatments for EDs, also provides evidence of support for psychedelics, including ketamine. "I think everybody responds different to all sorts of treatment for eating disorders. I think it is essential to be open minded in regards to treatment." [131] Importantly, patients expressed concern over psychedelics regarding safety, therapeutic setting, and trust among medical stakeholders, which they stated could be remedied through a priori education, controlled monitoring, and routine follow-up. Another qualitative study explored participant experiences with ceremonial ayahuasca and conventional therapy for AN and $\mathrm{BN}(N=13)[132]$. Thematic analysis revealed that ayahuasca produced rapid reductions in ED cognitions and behavior, allowed for painful memories and associated emotions to be processed, and catalyzed transcendent aspects of healing. Finally, Springs et al. investigated acute psychological effects of psychedelics in lifetime ED sufferers $(N=28)$, reporting significant improvements in depression and well-being [133]. Taken together, and with the relevant literature on ketamine, these findings underscore the desire to develop and test psychedelic interventions for EDs, as well as their potential therapeutic value. Findings additionally emphasize key methodological considerations in trial design, which have already begun to inform study protocols [134].

Future work should aim to investigate, establish, and optimize ketamine dose, duration, and frequency for EDs, in effort to support clinical recommendations and practice guidelines. Open-pilot studies and statistically-powered feasibility, randomized, and implementation trials are therefore warranted. Moreover, empirically-derived, standardized treatment regimens and outcome measures are suggested to facilitate comparisons across studies. Longitudinal assessments are also recommended to characterize clinical response for severe and enduring patients. Given that ketamine may normalize glutamatergic dysfunction implicated in EDs [135,136], promotes synaptogenesis and neuroplasticity [137140] with a critical window following administration [141], and has a short duration to relapse (2-6 weeks) [105], it is critical ketamine be combined with psychotherapy moving forward, either adjunctively or concurrently. A growing body of literature has subsequently identified strategies to prolong its antidepressant effect, including KAP $[142,143]$. Ragnhildstveit et al. were the first to report on serial KAP used to treat extreme and enduring BN, which utilized a person-centered, humanistic approach to psychotherapy, and resulted in complete and sustained remission [121]. The authors postulated that ketamine and psychotherapy act synergistically, with therapy augmenting the response to treatment, and repeated sessions accounting for the durability of effect. Furthermore, the "emergence phenomena" of ketamine [144], characterized by euphoria, lucid dreams, and hallucinations, may facilitate therapeutic rapport, patient-provider bonding and ultimately behavior change $[145,146]$. While treatment course should permit flexible dosing and individualization, KAP generally follows a three-step model, consisting of preparatory psychotherapy (step 1), ketamine dosing (step 2), and integration psychotherapy (step 3). Discussing patients' motives, intentions, and expectations for treatment, evaluating their current psychophysiological status, and providing a therapeutic environment conducive to the ketamine experience (i.e., "set and setting") are essential factors to consider prior to treatment. Examining different psychotherapeutic approaches in this 
context is additionally recommended, which has progressively diversified over the years to include cognitive-behavioral [147], humanistic [121,148], functional-analytic [149], and somatic-based interactional [150] therapy.

\section{Conclusion}

The evidence presented here provides a conceptual, yet concise, summary of the use of ketamine in treating EDs. While the relevant literature remains small, studies signal therapeutic potential for this complex and largely under-researched population. In particular, ketamine may provide the greatest utility to clinical non-responders, who are treatment-resistant to psychological and pharmacological interventions used in standard practice, and of whom are prone to developing protracted ED pathology. Further research is necessary to explore the effects of ketamine on ED symptomatology and psychopathology, specifically across subgroups - critically in BN, BED, and AFRID-; across diagnostic-dependent severity types (mild, moderate, severe, and extreme); as well as across the lifespan from children to older adults. Data can then be leveraged to establish safety profiles and inform targeted treatment strategies. Adjunctive and combination therapies, namely KAP, also provide avenues for empirical investigation, and for determining which contexts and interventional frameworks ketamine is best suited.

Author Contributions: Conceptualization, A.R.; investigation, A.R. and M.S.; writing-original draft preparation, A.R.; writing-review and editing, M.S., L.K.J, M.B., S.A., W.H., C.M., K.S., P.S. and R.R; supervision, P.S. and R.R; project administration, M.S and W.H. All authors have read and agreed to the published version of the manuscript.

Funding: This research received no external funding.

Conflicts of Interest: The authors declare no conflict of interest.

\section{References}

1. Schmidt, U.; Adan, R.; Boehm, I.; Campbell, I.C.; Dingemans, A.; Ehrlich, S.; Elzakkers, I.; Favaro, A.; Giel, K.; Harrison, A.; et al. Eating Disorders: The Big Issue. Lancet Psychiatry 2016, 3, 313-315, doi:10.1016/S2215-0366(16)00081-X.

2. Treasure, J.; Duarte, T.A.; Schmidt, U. Eating Disorders. The Lancet 2020, 395, 899-911, doi:10.1016/S0140-6736(20)30059-3.

3. Allen, K.L.; Byrne, S.M.; Oddy, W.H.; Crosby, R.D. DSM-IV-TR and DSM-5 Eating Disorders in Adolescents: Prevalence, Stability, and Psychosocial Correlates in a Population-Based Sample of Male and Female Adolescents. J. Abnorm. Psychol. 2013, 122, 720-732, doi:10.1037/a0034004.

4. Sheehan, D.V.; Herman, B.K. The Psychological and Medical Factors Associated With Untreated Binge Eating Disorder. Prim. Care Companion CNS Disord. 2015, 17, 27178, doi:10.4088/PCC.14r01732.

5. Mehler, P.S.; Brown, C. Anorexia Nervosa - Medical Complications. J. Eat. Disord. 2015, 3, 11, doi:10.1186/s40337-015-0040-8.

6. Mehler, P.S.; Rylander, M. Bulimia Nervosa - Medical Complications. J. Eat. Disord. 2015, 3, 12, doi:10.1186/s40337-015-0044-4.

7. Smink, F.R.E.; van Hoeken, D.; Hoek, H.W. Epidemiology of Eating Disorders: Incidence, Prevalence and Mortality Rates. Curr. Psychiatry Rep. 2012, 14, 406-414, doi:10.1007/s11920-012-0282-y.

8. Cardi, V.; Tchanturia, K.; Treasure, J. Premorbid and Illness-Related Social Difficulties in Eating Disorders: An Overview of the Literature and Treatment Developments. Curr. Neuropharmacol. 2018, 16, 1122-1130, doi:10.2174/1570159x16666180118100028.

9. Hay, P.; Mitchison, D.; Collado, A.E.L.; González-Chica, D.A.; Stocks, N.; Touyz, S. Burden and Health-Related Quality of Life of Eating Disorders, Including Avoidant/Restrictive Food Intake Disorder (ARFID), in the Australian Population. J. Eat. Disord. 2017, 5, 21, doi:10.1186/s40337-017-0149-z.

10. Mitchison, D.; Hay, P.; Slewa-Younan, S.; Mond, J. Time Trends in Population Prevalence of Eating Disorder Behaviors and Their Relationship to Quality of Life. PLoS ONE 2012, 7, 1-7, doi:10.1371/journal.pone.0048450.

11. Mond, J.; Hay, P.; Rodgers, B.; Owen, C. Quality of Life Impairment in a Community Sample of Women with Eating Disorders. Aust. N. Z. J. Psychiatry 2012, 46, 561-568, doi:10.1177/0004867411433967.

12. Ágh, T.; Kovács, G.; Supina, D.; Pawaskar, M.; Herman, B.K.; Vokó, Z.; Sheehan, D.V. A Systematic Review of the HealthRelated Quality of Life and Economic Burdens of Anorexia Nervosa, Bulimia Nervosa, and Binge Eating Disorder. Eat. Weight Disord. - Stud. Anorex. Bulim. Obes. 2016, 21, 353-364, doi:10.1007/s40519-016-0264-x.

13. Deloitte Access Economics The Social and Economic Cost of Eating Disorders in the United States of America: A Report for the Strategic Training Initiative for the Prevention of Eating Disorders and the Academy for Eating Disorders Available online: https://www.hsph.harvard.edu/striped/report-economic-costs-of-eating-disorders/ (accessed on 1 February 2022). 
14. Madden, S.; Morris, A.; Zurynski, Y.A.; Kohn, M.; Elliot, E.J. Burden of Eating Disorders in 5-13-Year-Old Children in Australia. Med. J. Aust. 2009, 190, 410-414, doi:10.5694/j.1326-5377.2009.tb02487.x.

15. Hay, P.; Girosi, F.; Mond, J. Prevalence and Sociodemographic Correlates of DSM-5 Eating Disorders in the Australian Population. J. Eat. Disord. 2015, doi:10.1186/s40337-015-0056-0.

16. Galmiche, M.; Déchelotte, P.; Lambert, G.; Tavolacci, M.P. Prevalence of Eating Disorders over the 2000-2018 Period: A Systematic Literature Review. Am. J. Clin. Nutr. 2019, 109, 1402-1413, doi:10.1093/ajcn/nqy342.

17. Qian, J.; Wu, Y.; Liu, F.; Zhu, Y.; Jin, H.; Zhang, H.; Wan, Y.; Li, C.; Yu, D. An Update on the Prevalence of Eating Disorders in the General Population: A Systematic Review and Meta-Analysis. Eat. Weight Disord. - Stud. Anorex. Bulim. Obes. 2021, doi:10.1007/s40519-021-01162-z.

18. Crow, S.J.; Peterson, C.B.; Swanson, S.A.; Raymond, N.C.; Specker, S.; Eckert, E.D.; Mitchell, J.E. Increased Mortality in Bulimia Nervosa and Other Eating Disorders. Am. J. Psychiatry 2009, 166, 1342-1346, doi:10.1176/appi.ajp.2009.09020247.

19. Arcelus, J.; Mitchell, A.J.; Wales, J.; Nielsen, S. Mortality Rates in Patients With Anorexia Nervosa and Other Eating Disorders: A Meta-Analysis of 36 Studies. Arch. Gen. Psychiatry 2011, 68, 724-731, doi:10.1001/archgenpsychiatry.2011.74.

20. Birmingham, C.L.; Su, J.; Hlynsky, J.A.; Goldner, E.M.; Gao, M. The Mortality Rate from Anorexia Nervosa. Int. J. Eat. Disord. 2005, 38, 143-146, doi:10.1002/eat.20164.

21. Papadopoulos, F.C.; Ekbom, A.; Brandt, L.; Ekselius, L. Excess Mortality, Causes of Death and Prognostic Factors in Anorexia Nervosa. Br. J. Psychiatry 2009, 194, 10-17, doi:10.1192/bjp.bp.108.054742.

22. Franko, D.L.; Keshaviah, A.; Eddy, K.T.; Krishna, M.; Davis, M.C.; Keel, P.K.; Herzog, D.B. A Longitudinal Investigation of Mortality in Anorexia Nervosa and Bulimia Nervosa. Am. J. Psychiatry 2013, 170, 917-925, doi:10.1176/appi.ajp.2013.12070868.

23. King, J.A.; Frank, G.K.W.; Thompson, P.M.; Ehrlich, S. Structural Neuroimaging of Anorexia Nervosa: Future Directions in the Quest for Mechanisms Underlying Dynamic Alterations. Biol. Psychiatry 2018, 83, 224-234, doi:10.1016/j.biopsych.2017.08.011.

24. Frank, G.K.W.; Shott, M.E.; DeGuzman, M.C. The Neurobiology of Eating Disorders. Child Adolesc. Psychiatr. Clin. N. Am. 2019, 28, 629-640, doi:10.1016/j.chc.2019.05.007.

25. Finch, J.E.; Palumbo, I.M.; Tobin, K.E.; Latzman, R.D. Structural Brain Correlates of Eating Pathology Symptom Dimensions: A Systematic Review. Psychiatry Res. Neuroimaging 2021, 317, 111379, doi:10.1016/j.pscychresns.2021.111379.

26. Frank, G.K.W. Neuroimaging and Eating Disorders. Curr. Opin. Psychiatry 2019, 32, 478-483, doi:10.1097/YCO.0000000000000544.

27. Castro-Fornieles, J.; de la Serna, E.; Calvo, A.; Pariente, J.; Andrés-Perpiña, S.; Plana, M.T.; Romero, S.; Flamarique, I.; Gárriz, M.; Bargalló, N. Cortical Thickness 20 Years after Diagnosis of Anorexia Nervosa during Adolescence. Eur. Arch. Psychiatry Clin. Neurosci. 2021, 271, 1133-1139, doi:10.1007/s00406-019-00992-4.

28. Frank, G.K.W.; Favaro, A.; Marsh, R.; Ehrlich, S.; Lawson, E.A. Toward Valid and Reliable Brain Imaging Results in Eating Disorders. Int. J. Eat. Disord. 2018, 51, 250-261, doi:10.1002/eat.22829.

29. Biezonski, D.; Cha, J.; Steinglass, J.; Posner, J. Evidence for Thalamocortical Circuit Abnormalities and Associated Cognitive Dysfunctions in Underweight Individuals with Anorexia Nervosa. Neuropsychopharmacology 2016, 41, 1560-1568, doi:10.1038/npp.2015.314.

30. Boehm, I.; Geisler, D.; King, J.A.; Ritschel, F.; Seidel, M.; Deza Araujo, Y.; Petermann, J.; Lohmeier, H.; Weiss, J.; Walter, M.; et al. Increased Resting State Functional Connectivity in the Fronto-Parietal and Default Mode Network in Anorexia Nervosa. Front. Behav. Neurosci. 2014, 8.

31. Gaudio, S.; Piervincenzi, C.; Beomonte Zobel, B.; Romana Montecchi, F.; Riva, G.; Carducci, F.; Cosimo Quattrocchi, C. Altered Resting State Functional Connectivity of Anterior Cingulate Cortex in Drug Naïve Adolescents at the Earliest Stages of Anorexia Nervosa. Sci. Rep. 2015, 5, 10818, doi:10.1038/srep10818.

32. Kullmann, S.; Giel, K.E.; Teufel, M.; Thiel, A.; Zipfel, S.; Preissl, H. Aberrant Network Integrity of the Inferior Frontal Cortex in Women with Anorexia Nervosa. NeuroImage Clin. 2014, 4, 615-622, doi:10.1016/j.nicl.2014.04.002.

33. Park, B.; Moon, T.; Park, H. Dynamic Functional Connectivity Analysis Reveals Improved Association between Brain Networks and Eating Behaviors Compared to Static Analysis. Behav. Brain Res. 2018, 337, 114-121, doi:10.1016/j.bbr.2017.10.001.

34. Rangaprakash, D.; Bohon, C.; Lawrence, K.E.; Moody, T.; Morfini, F.; Khalsa, S.S.; Strober, M.; Feusner, J.D. Aberrant Dynamic Connectivity for Fear Processing in Anorexia Nervosa and Body Dysmorphic Disorder. Front. Psychiatry 2018, 9.

35. Stopyra, M.A.; Simon, J.J.; Skunde, M.; Walther, S.; Bendszus, M.; Herzog, W.; Friederich, H.-C. Altered Functional Connectivity in Binge Eating Disorder and Bulimia Nervosa: A Resting-State FMRI Study. Brain Behav. 2019, 9, e01207, doi:10.1002/brb3.1207.

36. Boehm, I.; Geisler, D.; Tam, F.; King, J.A.; Ritschel, F.; Seidel, M.; Bernardoni, F.; Murr, J.; Goschke, T.; Calhoun, V.D.; et al. Partially Restored Resting-State Functional Connectivity in Women Recovered from Anorexia Nervosa. J. Psychiatry Neurosci. 2016, 41, 377-385, doi:10.1503/jpn.150259.

37. Cowdrey, F.A.; Filippini, N.; Park, R.J.; Smith, S.M.; McCabe, C. Increased Resting State Functional Connectivity in the Default Mode Network in Recovered Anorexia Nervosa. Hum. Brain Mapp. 2014, 35, 483-491, doi:10.1002/hbm.22202.

38. Domakonda, M.J.; He, X.; Lee, S.; Cyr, M.; Marsh, R. Increased Functional Connectivity Between Ventral Attention and Default Mode Networks in Adolescents with Bulimia Nervosa. J. Am. Acad. Child Adolesc. Psychiatry 2019, 58, 232-241, doi:10.1016/j.jaac.2018.09.433. 
39. Cha, J.; Ide, J.S.; Bowman, F.D.; Simpson, H.B.; Posner, J.; Steinglass, J.E. Abnormal Reward Circuitry in Anorexia Nervosa: A Longitudinal, Multimodal MRI Study. Hum. Brain Mapp. 2016, 37, 3835-3846, doi:10.1002/hbm.23279.

40. Ehrlich, S.; Lord, A.R.; Geisler, D.; Borchardt, V.; Boehm, I.; Seidel, M.; Ritschel, F.; Schulze, A.; King, J.A.; Weidner, K.; et al. Reduced Functional Connectivity in the Thalamo-Insular Subnetwork in Patients with Acute Anorexia Nervosa. Hum. Brain Mapp. 2015, 36, 1772-1781, doi:10.1002/hbm.22736.

41. Geisler, D.; Borchardt, V.; Lord, A.R.; Boehm, I.; Ritschel, F.; Zwipp, J.; Clas, S.; King, J.A.; Wolff-Stephan, S.; Roessner, V.; et al. Abnormal Functional Global and Local Brain Connectivity in Female Patients with Anorexia Nervosa. J. Psychiatry Neurosci. 2016, 41, 6-15, doi:10.1503/jpn.140310.

42. Haynos, A.F.; Hall, L.M.J.; Lavender, J.M.; Peterson, C.B.; Crow, S.J.; Klimes-Dougan, B.; Cullen, K.R.; Lim, K.O.; Camchong, J. Resting State Functional Connectivity of Networks Associated with Reward and Habit in Anorexia Nervosa. Hum. Brain Mapp. 2019, 40, 652-662, doi:10.1002/hbm.24402.

43. Monteleone, A.M.; Castellini, G.; Volpe, U.; Ricca, V.; Lelli, L.; Monteleone, P.; Maj, M. Neuroendocrinology and Brain Imaging of Reward in Eating Disorders: A Possible Key to the Treatment of Anorexia Nervosa and Bulimia Nervosa. Prog. Neuropsychopharmacol. Biol. Psychiatry 2018, 80, 132-142, doi:10.1016/j.pnpbp.2017.02.020.

44. Kim, K.R.; Ku, J.; Lee, J.-H.; Lee, H.; Jung, Y.-C. Functional and Effective Connectivity of Anterior Insula in Anorexia Nervosa and Bulimia Nervosa. Neurosci. Lett. 2012, 521, 152-157, doi:10.1016/j.neulet.2012.05.075.

45. Lee, S.; Ran Kim, K.; Ku, J.; Lee, J.-H.; Namkoong, K.; Jung, Y.-C. Resting-State Synchrony between Anterior Cingulate Cortex and Precuneus Relates to Body Shape Concern in Anorexia Nervosa and Bulimia Nervosa. Psychiatry Res. 2014, 221, 43-48, doi:10.1016/j.pscychresns.2013.11.004.

46. McFadden, K.L.; Tregellas, J.R.; Shott, M.E.; Frank, G.K.W. Reduced Salience and Default Mode Network Activity in Women with Anorexia Nervosa. J. Psychiatry Neurosci. JPN 2014, 39, 178-188, doi:10.1503/jpn.130046.

47. Heine, L.; Soddu, A.; Gómez, F.; Vanhaudenhuyse, A.; Tshibanda, L.; Thonnard, M.; Charland-Verville, V.; Kirsch, M.; Laureys, S.; Demertzi, A. Resting State Networks and Consciousness: Alterations of Multiple Resting State Network Connectivity in Physiological, Pharmacological, and Pathological Consciousness States. Front. Psychol. 2012, 3, 295, doi:10.3389/fpsyg.2012.00295.

48. Vocks, S.; Tuschen-Caffier, B.; Pietrowsky, R.; Rustenbach, S.J.; Kersting, A.; Herpertz, S. Meta-Analysis of the Effectiveness of Psychological and Pharmacological Treatments for Binge Eating Disorder. Int. J. Eat. Disord. 2010, 43, 205-217, doi:10.1002/eat.20696.

49. Hilbert, A.; Hoek, H.W.; Schmidt, R. Evidence-Based Clinical Guidelines for Eating Disorders: International Comparison. Curr. Opin. Psychiatry 2017, 30, 423-437, doi:10.1097/YCO.0000000000000360.

50. Hay, P.J.; Touyz, S.; Claudino, A.M.; Lujic, S.; Smith, C.A.; Madden, S. Inpatient versus Outpatient Care, Partial Hospitalisation and Waiting List for People with Eating Disorders. Cochrane Database Syst. Rev. 2019, 1, CD010827, doi:10.1002/14651858.CD010827.pub2.

51. de Jong, M.; Schoorl, M.; Hoek, H.W. Enhanced Cognitive Behavioural Therapy for Patients with Eating Disorders: A Systematic Review. Curr. Opin. Psychiatry 2018, 31, 436-444, doi:10.1097/YCO.0000000000000452.

52. Svaldi, J.; Schmitz, F.; Baur, J.; Hartmann, A.S.; Legenbauer, T.; Thaler, C.; von Wietersheim, J.; de Zwaan, M.; TuschenCaffier, B. Efficacy of Psychotherapies and Pharmacotherapies for Bulimia Nervosa. Psychol. Med. 2019, 49, 898-910, doi:10.1017/S0033291718003525.

53. Peat, C.M.; Berkman, N.D.; Lohr, K.N.; Brownley, K.A.; Bann, C.M.; Cullen, K.; Quattlebaum, M.J.; Bulik, C.M. Comparative Effectiveness of Treatments for Binge-Eating Disorder: Systematic Review and Network Meta-Analysis. Eur. Eat. Disord. Rev. J. Eat. Disord. Assoc. 2017, 25, 317-328, doi:10.1002/erv.2517.

54. van den Berg, E.; Houtzager, L.; de Vos, J.; Daemen, I.; Katsaragaki, G.; Karyotaki, E.; Cuijpers, P.; Dekker, J. Meta-Analysis on the Efficacy of Psychological Treatments for Anorexia Nervosa. Eur. Eat. Disord. Rev. J. Eat. Disord. Assoc. 2019, 27, 331-351, doi:10.1002/erv.2683.

55. Zipfel, S.; Wild, B.; Groß, G.; Friederich, H.-C.; Teufel, M.; Schellberg, D.; Giel, K.E.; de Zwaan, M.; Dinkel, A.; Herpertz, S.; et al. Focal Psychodynamic Therapy, Cognitive Behaviour Therapy, and Optimised Treatment as Usual in Outpatients with Anorexia Nervosa (ANTOP Study): Randomised Controlled Trial. Lancet Lond. Engl. 2014, 383, 127-137, doi:10.1016/S01406736(13)61746-8.

56. Hans-Christoph, F.; Beate, W.; Stephan, Z.; Henning, S.; Wolfgang, H. Anorexia Nervosa - Focal Psychodynamic Psychotherapy: Theoretical Basis and User Manual; Hogrefe Publishing, 2019; ISBN 978-1-61334-554-2.

57. McIntosh, V.V.W.; Jordan, J.; Carter, F.A.; Luty, S.E.; McKenzie, J.M.; Bulik, C.M.; Frampton, C.M.A.; Joyce, P.R. Three Psychotherapies for Anorexia Nervosa: A Randomized, Controlled Trial. Am. J. Psychiatry 2005, 162, 741-747, doi:10.1176/appi.ajp.162.4.741.

58. Touyz, S.; Le Grange, D.; Lacey, H.; Hay, P.; Smith, R.; Maguire, S.; Bamford, B.; Pike, K.M.; Crosby, R.D. Treating Severe and Enduring Anorexia Nervosa: A Randomized Controlled Trial. Psychol. Med. 2013, 43, 2501-2511, doi:10.1017/S0033291713000949.

59. Schmidt, U.; Magill, N.; Renwick, B.; Keyes, A.; Kenyon, M.; Dejong, H.; Lose, A.; Broadbent, H.; Loomes, R.; Yasin, H.; et al. The Maudsley Outpatient Study of Treatments for Anorexia Nervosa and Related Conditions (MOSAIC): Comparison of the Maudsley Model of Anorexia Nervosa Treatment for Adults (MANTRA) with Specialist Supportive Clinical Management 
(SSCM) in Outpatients with Broadly Defined Anorexia Nervosa: A Randomized Controlled Trial. J. Consult. Clin. Psychol. 2015, 83, 796-807, doi:10.1037/ccp0000019.

60. Schmidt, U.; Startup, H.; Treasure, J. A Cognitive Interpersonal Therapy Workbook for Treating Anorexia Nervosa: The Maudsley Model; Routledge: London, 2018; ISBN 978-1-315-72848-3.

61. Agras, W.S.; Lock, J.; Brandt, H.; Bryson, S.W.; Dodge, E.; Halmi, K.A.; Jo, B.; Johnson, C.; Kaye, W.; Wilfley, D.; et al. Comparison of 2 Family Therapies for Adolescent Anorexia Nervosa: A Randomized Parallel Trial. JAMA Psychiatry 2014, 71, 1279-1286, doi:10.1001/jamapsychiatry.2014.1025.

62. Eisler, I.; Simic, M.; Hodsoll, J.; Asen, E.; Berelowitz, M.; Connan, F.; Ellis, G.; Hugo, P.; Schmidt, U.; Treasure, J.; et al. A Pragmatic Randomised Multi-Centre Trial of Multifamily and Single Family Therapy for Adolescent Anorexia Nervosa. BMC Psychiatry 2016, 16, 422, doi:10.1186/s12888-016-1129-6.

63. Le Grange, D.; Hughes, E.K.; Court, A.; Yeo, M.; Crosby, R.D.; Sawyer, S.M. Randomized Clinical Trial of Parent-Focused Treatment and Family-Based Treatment for Adolescent Anorexia Nervosa. J. Am. Acad. Child Adolesc. Psychiatry 2016, 55, 683692, doi:10.1016/j.jaac.2016.05.007.

64. Himmerich, H.; Kan, C.; Au, K.; Treasure, J. Pharmacological Treatment of Eating Disorders, Comorbid Mental Health Problems, Malnutrition and Physical Health Consequences. Pharmacol. Ther. 2021, 217, 107667, doi:10.1016/j.pharmthera.2020.107667.

65. McElroy, S.L.; Guerdjikova, A.I.; Mori, N.; Romo-Nava, F. Progress in Developing Pharmacologic Agents to Treat Bulimia Nervosa. CNS Drugs 2019, 33, 31-46, doi:10.1007/s40263-018-0594-5.

66. Himmerich, H.; Benkert, O. Medikamente zur Behandlung von Essstörungen und Adipositas. In Kompendium der Psychiatrischen Pharmakotherapie; Benkert, O., Hippius, H., Eds.; Springer: Berlin, Heidelberg, 2021; pp. 739-758 ISBN 978-3-662-617533.

67. Appolinario, J.C.; Nardi, A.E.; McElroy, S.L. Investigational Drugs for the Treatment of Binge Eating Disorder (BED): An Update. Expert Opin. Investig. Drugs 2019, 28, 1081-1094, doi:10.1080/13543784.2019.1692813.

68. Dold, M.; Aigner, M.; Klabunde, M.; Treasure, J.; Kasper, S. Second-Generation Antipsychotic Drugs in Anorexia Nervosa: A Meta-Analysis of Randomized Controlled Trials. Psychother. Psychosom. 2015, 84, 110-116, doi:10.1159/000369978.

69. Attia, E.; Steinglass, J.E.; Walsh, B.T.; Wang, Y.; Wu, P.; Schreyer, C.; Wildes, J.; Yilmaz, Z.; Guarda, A.S.; Kaplan, A.S.; et al. Olanzapine Versus Placebo in Adult Outpatients With Anorexia Nervosa: A Randomized Clinical Trial. Am. J. Psychiatry 2019, 176, 449-456, doi:10.1176/appi.ajp.2018.18101125.

70. Frank, G.K.W.; Shott, M.E.; Hagman, J.O.; Schiel, M.A.; DeGuzman, M.C.; Rossi, B. The Partial Dopamine D2 Receptor Agonist Aripiprazole Is Associated with Weight Gain in Adolescent Anorexia Nervosa. Int. J. Eat. Disord. 2017, 50, 447-450, doi:10.1002/eat.22704.

71. Mitchell, J.E.; Peterson, C.B. Anorexia Nervosa. N. Engl. J. Med. 2020, 382, 1343-1351, doi:10.1056/NEJMcp1803175.

72. Blanchet, C.; Guillaume, S.; Bat-Pitault, F.; Carles, M.-E.; Clarke, J.; Dodin, V.; Duriez, P.; Gerardin, P.; Hanachi-Guidoum, M.; Iceta, S.; et al. Medication in AN: A Multidisciplinary Overview of Meta-Analyses and Systematic Reviews. J. Clin. Med. 2019, 8, E278, doi:10.3390/jcm8020278.

73. van Hoeken, D; Hoek, H.W. Review of the Burden of Eating Disorders: Mortality, Disability, Costs, Quality of Life, and Family Burden. Curr. Opin. Psychiatry 2020, 33, 521-527, doi:10.1097/YCO.0000000000000641.

74. Fichter, M.M.; Quadflieg, N.; Crosby, R.D.; Koch, S. Long-Term Outcome of Anorexia Nervosa: Results from a Large Clinical Longitudinal Study. Int. J. Eat. Disord. 2017, 50, 1018-1030, doi:10.1002/eat.22736.

75. Quadflieg, N.; Fichter, M.M. Long-Term Outcome of Inpatients with Bulimia Nervosa-Results from the Christina Barz Study. Int. J. Eat. Disord. 2019, 52, 834-845, doi:10.1002/eat.23084.

76. Fichter, M.M.; Quadflieg, N.; Hedlund, S. Long-Term Course of Binge Eating Disorder and Bulimia Nervosa: Relevance for Nosology and Diagnostic Criteria. Int. J. Eat. Disord. 2008, 41, 577-586, doi:10.1002/eat.20539.

77. Steinhausen, H.-C. The Outcome of Anorexia Nervosa in the 20th Century. Am. J. Psychiatry 2002, 159, 1284-1293, doi:10.1176/appi.ajp.159.8.1284.

78. Steinhausen, H.-C.; Weber, S. The Outcome of Bulimia Nervosa: Findings from One-Quarter Century of Research. Am. J. Psychiatry 2009, 166, 1331-1341, doi:10.1176/appi.ajp.2009.09040582.

79. Eddy, K.T.; Tabri, N.; Thomas, J.J.; Murray, H.B.; Keshaviah, A.; Hastings, E.; Edkins, K.; Krishna, M.; Herzog, D.B.; Keel, P.K.; et al. Recovery From Anorexia Nervosa and Bulimia Nervosa at 22-Year Follow-Up. J. Clin. Psychiatry 2017, 78, 184-189, doi:10.4088/JCP.15m10393.

80. Robinson, P Severe and Enduring Eating Disorder (SEED): Management of Complex Presentations of Anorexia and Bulimia Nervosa I Wiley Available online: https:/www.wiley.com/en-us/Severe+and+Enduring+Eating+Disorder+\%28SEED\%29\%3A+Management+of+Complex+Presentations+of+Anorexia+and+Bulimia+Nervosa-p-9780470062074 (accessed on 1 February 2022).

81. Treasure, J.; Stein, D.; Maguire, S. Has the Time Come for a Staging Model to Map the Course of Eating Disorders from High Risk to Severe Enduring Illness? An Examination of the Evidence. Early Interv. Psychiatry 2015, 9, 173-184, doi:10.1111/eip.12170.

82. Kotilahti, E.; West, M.; Isomaa, R.; Karhunen, L.; Rocks, T.; Ruusunen, A. Treatment Interventions for Severe and Enduring Eating Disorders: Systematic Review. Int. J. Eat. Disord. 2020, 53, 1280-1302, doi:10.1002/eat.23322. 
83. Hay, P.; Chinn, D.; Forbes, D.; Madden, S.; Newton, R.; Sugenor, L.; Touyz, S.; Ward, W.; Royal Australian and New Zealand College of Psychiatrists Royal Australian and New Zealand College of Psychiatrists Clinical Practice Guidelines for the Treatment of Eating Disorders. Aust. N. Z. J. Psychiatry 2014, 48, 977-1008, doi:10.1177/0004867414555814.

84. Wonderlich, S.; Mitchell, J.E.; Crosby, R.D.; Myers, T.C.; Kadlec, K.; Lahaise, K.; Swan-Kremeier, L.; Dokken, J.; Lange, M.; Dinkel, J.; et al. Minimizing and Treating Chronicity in the Eating Disorders: A Clinical Overview. Int. J. Eat. Disord. 2012, 45, 467-475, doi:10.1002/eat.20978.

85. Strober, M.; Johnson, C. The Need for Complex Ideas in Anorexia Nervosa: Why Biology, Environment, and Psyche All Matter, Why Therapists Make Mistakes, and Why Clinical Benchmarks Are Needed for Managing Weight Correction. Int. J. Eat. Disord. 2012, 45, 155-178, doi:10.1002/eat.22005.

86. Westmoreland, P.; Mehler, P.S. Caring for Patients With Severe and Enduring Eating Disorders (SEED): Certification, Harm Reduction, Palliative Care, and the Question of Futility. J. Psychiatr. Pract. 2016, 22, 313-320, doi:10.1097/PRA.0000000000000160.

87. Strand, M.; Sjöstrand, M.; Lindblad, A. A Palliative Care Approach in Psychiatry: Clinical Implications. BMC Med. Ethics 2020, 21, 29, doi:10.1186/s12910-020-00472-8.

88. Erskine, H.E.; Whiteford, H.A.; Pike, K.M. The Global Burden of Eating Disorders. Curr. Opin. Psychiatry 2016, 29, 346-353, doi:10.1097/YCO.0000000000000276.

89. Domino, E.F.; Chodoff, P.; Corssen, G. PHARMACOLOGIC EFFECTS OF CI-581, A NEW DISSOCIATIVE ANESTHETIC, IN MAN. Clin. Pharmacol. Ther. 1965, 6, 279-291, doi:10.1002/cpt196563279.

90. Dundee, J.W.; Knox, J.W.; Black, G.W.; Moore, J.; Pandit, S.K.; Bovill, J.; Clarke, R.S.; Love, S.H.; Elliott, J.; Coppel, D.L. Ketamine as an Induction Agent in Anaesthetics. Lancet Lond. Engl. 1970, 1, 1370-1371, doi:10.1016/s0140-6736(70)91273-0.

91. Domino, E.F.; Warner, D.S. Taming the Ketamine Tiger. Anesthesiology 2010, 113, 678-684, doi:10.1097/ALN.0b013e3181ed09a2.

92. Adams, J.D.; Castagnoli, N.; Trevor, A.J. Quantitative Analysis of Ketamine Enantiomers. Proc. West. Pharmacol. Soc. 1978, 21, 471-472.

93. Jelen, L.A.; Young, A.H.; Stone, J.M. Ketamine: A Tale of Two Enantiomers. J. Psychopharmacol. Oxf. Engl. 2021, 35, 109-123, doi:10.1177/0269881120959644.

94. Ebert, B.; Mikkelsen, S.; Thorkildsen, C.; Borgbjerg, F.M. Norketamine, the Main Metabolite of Ketamine, Is a Non-Competitive NMDA Receptor Antagonist in the Rat Cortex and Spinal Cord. Eur. J. Pharmacol. 1997, 333, 99-104, doi:10.1016/s00142999(97)01116-3.

95. White, P.F.; Ham, J.; Way, W.L.; Trevor, A.J. Pharmacology of Ketamine Isomers in Surgical Patients. Anesthesiology 1980, 52, 231-239, doi:10.1097/00000542-198003000-00008.

96. White, P.F.; Schüttler, J.; Shafer, A.; Stanski, D.R.; Horai, Y.; Trevor, A.J. Comparative Pharmacology of the Ketamine Isomers. Studies in Volunteers. Br. J. Anaesth. 1985, 57, 197-203, doi:10.1093/bja/57.2.197.

97. Mion, G.; Villevieille, T. Ketamine Pharmacology: An Update (Pharmacodynamics and Molecular Aspects, Recent Findings). CNS Neurosci. Ther. 2013, 19, 370-380, doi:10.1111/cns.12099.

98. Lener, M.S.; Niciu, M.J.; Ballard, E.D.; Park, M.; Park, L.T.; Nugent, A.C.; Zarate, C.A. Glutamate and Gamma-Aminobutyric Acid Systems in the Pathophysiology of Major Depression and Antidepressant Response to Ketamine. Biol. Psychiatry 2017, 81, 886-897, doi:10.1016/j.biopsych.2016.05.005.

99. Berman, R.M.; Cappiello, A.; Anand, A.; Oren, D.A.; Heninger, G.R.; Charney, D.S.; Krystal, J.H. Antidepressant Effects of Ketamine in Depressed Patients. Biol. Psychiatry 2000, 47, 351-354, doi:10.1016/s0006-3223(99)00230-9.

100. Zarate, C.A.; Singh, J.B.; Carlson, P.J.; Brutsche, N.E.; Ameli, R.; Luckenbaugh, D.A.; Charney, D.S.; Manji, H.K. A Randomized Trial of an N-Methyl-D-Aspartate Antagonist in Treatment-Resistant Major Depression. Arch. Gen. Psychiatry 2006, 63, 856-864, doi:10.1001/archpsyc.63.8.856.

101. Diazgranados, N.; Ibrahim, L.; Brutsche, N.E.; Newberg, A.; Kronstein, P.; Khalife, S.; Kammerer, W.A.; Quezado, Z.; Luckenbaugh, D.A.; Salvadore, G.; et al. A Randomized Add-on Trial of an N-Methyl-D-Aspartate Antagonist in Treatment-Resistant Bipolar Depression. Arch. Gen. Psychiatry 2010, 67, 793-802, doi:10.1001/archgenpsychiatry.2010.90.

102. Zarate, C.A.; Brutsche, N.E.; Ibrahim, L.; Franco-Chaves, J.; Diazgranados, N.; Cravchik, A.; Selter, J.; Marquardt, C.A.; Liberty, V.; Luckenbaugh, D.A. Replication of Ketamine's Antidepressant Efficacy in Bipolar Depression: A Randomized Controlled Add-on Trial. Biol. Psychiatry 2012, 71, 939-946, doi:10.1016/j.biopsych.2011.12.010.

103. Ionescu, D.F.; Luckenbaugh, D.A.; Niciu, M.J.; Richards, E.M.; Zarate, C.A. A Single Infusion of Ketamine Improves Depression Scores in Patients with Anxious Bipolar Depression. Bipolar Disord. 2015, 17, 438-443, doi:10.1111/bdi.12277.

104. Hu, Y.-D.; Xiang, Y.-T.; Fang, J.-X.; Zu, S.; Sha, S.; Shi, H.; Ungvari, G.S.; Correll, C.U.; Chiu, H.F.K.; Xue, Y.; et al. Single i.v. Ketamine Augmentation of Newly Initiated Escitalopram for Major Depression: Results from a Randomized, Placebo-Controlled 4-Week Study. Psychol. Med. 2016, 46, 623-635, doi:10.1017/S0033291715002159.

105. Marcantoni, W.S.; Akoumba, B.S.; Wassef, M.; Mayrand, J.; Lai, H.; Richard-Devantoy, S.; Beauchamp, S. A Systematic Review and Meta-Analysis of the Efficacy of Intravenous Ketamine Infusion for Treatment Resistant Depression: January 2009 January 2019. J. Affect. Disord. 2020, 277, 831-841, doi:10.1016/j.jad.2020.09.007.

106. Kryst, J.; Kawalec, P.; Mitoraj, A.M.; Pilc, A.; Lasoń, W.; Brzostek, T. Efficacy of Single and Repeated Administration of Ketamine in Unipolar and Bipolar Depression: A Meta-Analysis of Randomized Clinical Trials. Pharmacol. Rep. PR 2020, 72, 543562, doi:10.1007/s43440-020-00097-z. 
107. Xiong, J.; Lipsitz, O.; Chen-Li, D.; Rosenblat, J.D.; Rodrigues, N.B.; Carvalho, I.; Lui, L.M.W.; Gill, H.; Narsi, F.; Mansur, R.B.; et al. The Acute Antisuicidal Effects of Single-Dose Intravenous Ketamine and Intranasal Esketamine in Individuals with Major Depression and Bipolar Disorders: A Systematic Review and Meta-Analysis. J. Psychiatr. Res. 2021, 134, 57-68, doi:10.1016/j.jpsychires.2020.12.038.

108. Conley, A.A.; Norwood, A.E.Q.; Hatvany, T.C.; Griffith, J.D.; Barber, K.E. Efficacy of Ketamine for Major Depressive Episodes at 2, 4, and 6-Weeks Post-Treatment: A Meta-Analysis. Psychopharmacology (Berl.) 2021, 238, 1737-1752, doi:10.1007/s00213021-05825-8.

109. Daly, E.J.; Trivedi, M.H.; Janik, A.; Li, H.; Zhang, Y.; Li, X.; Lane, R.; Lim, P.; Duca, A.R.; Hough, D.; et al. Efficacy of Esketamine Nasal Spray Plus Oral Antidepressant Treatment for Relapse Prevention in Patients With Treatment-Resistant Depression: A Randomized Clinical Trial. JAMA Psychiatry 2019, 76, 893-903, doi:10.1001/jamapsychiatry.2019.1189.

110. Fedgchin, M.; Trivedi, M.; Daly, E.J.; Melkote, R.; Lane, R.; Lim, P.; Vitagliano, D.; Blier, P.; Fava, M.; Liebowitz, M.; et al. Efficacy and Safety of Fixed-Dose Esketamine Nasal Spray Combined With a New Oral Antidepressant in Treatment-Resistant Depression: Results of a Randomized, Double-Blind, Active-Controlled Study (TRANSFORM-1). Int. J. Neuropsychopharmacol. 2019, 22, 616-630, doi:10.1093/ijnp/pyz039.

111. Peyrovian, B.; McIntyre, R.S.; Phan, L.; Lui, L.M.W.; Gill, H.; Majeed, A.; Chen-Li, D.; Nasri, F.; Rosenblat, J.D. Registered Clinical Trials Investigating Ketamine for Psychiatric Disorders. J. Psychiatr. Res. 2020, 127, 1-12, doi:10.1016/j.jpsychires.2020.03.020.

112. Siegel, A.N.; Meshkat, S.; Benitah, K.; Lipsitz, O.; Gill, H.; Lui, L.M.W.; Teopiz, K.M.; McIntyre, R.S.; Rosenblat, J.D. Registered Clinical Studies Investigating Psychedelic Drugs for Psychiatric Disorders. J. Psychiatr. Res. 2021, 139, 71-81, doi:10.1016/j.jpsychires.2021.05.019.

113. Martinotti, G.; Chiappini, S.; Pettorruso, M.; Mosca, A.; Miuli, A.; Di Carlo, F.; D' Andrea, G.; Collevecchio, R.; Di Muzio, I.; Sensi, S.L.; et al. Therapeutic Potentials of Ketamine and Esketamine in Obsessive-Compulsive Disorder (OCD), Substance Use Disorders (SUD) and Eating Disorders (ED): A Review of the Current Literature. Brain Sci. 2021, 11, 856, doi:10.3390/brainsci11070856.

114. Liriano, F.; Hatten, C.; Schwartz, T.L. Ketamine as Treatment for Post-Traumatic Stress Disorder: A Review. Drugs Context 2019, 8, 212305, doi:10.7573/dic.212305.

115. Asim, M.; Wang, B.; Hao, B.; Wang, X. Ketamine for Post-Traumatic Stress Disorders and It's Possible Therapeutic Mechanism. Neurochem. Int. 2021, 146, 105044, doi:10.1016/j.neuint.2021.105044.

116. Strong, C.E.; Kabbaj, M. Neural Mechanisms Underlying the Rewarding and Therapeutic Effects of Ketamine as a Treatment for Alcohol Use Disorder. Front. Behav. Neurosci. 2020, 14, 593860, doi:10.3389/fnbeh.2020.593860.

117. Mills, I.H.; Park, G.R.; Manara, A.R.; Merriman, R.J. Treatment of Compulsive Behaviour in Eating Disorders with Intermittent Ketamine Infusions. QJM Mon. J. Assoc. Physicians 1998, 91, 493-503, doi:10.1093/qjmed/91.7.493.

118. Schwartz, T.; Trunko, M.E.; Feifel, D.; Lopez, E.; Peterson, D.; Frank, G.K.W.; Kaye, W. A Longitudinal Case Series of IM Ketamine for Patients with Severe and Enduring Eating Disorders and Comorbid Treatment-Resistant Depression. Clin. Case Rep. 2021, 9, e03869, doi:10.1002/ccr3.3869.

119. Scolnick, B.; Zupec-Kania, B.; Calabrese, L.; Aoki, C.; Hildebrandt, T. Remission from Chronic Anorexia Nervosa With Ketogenic Diet and Ketamine: Case Report. Front. Psychiatry 2020, 11, 763, doi:10.3389/fpsyt.2020.00763.

120. Dechant, E.; Boyle, B.; Ross, R.A. Ketamine in a Patient with Comorbid Anorexia and MDD. J. Womens Health Dev. 2020, 3 , 373-375.

121. Ragnhildstveit, A.; Jackson, L.K.; Cunningham, S.; Good, L.; Tanner, Q.; Roughan, M.; Henrie-Barrus, P. Case Report: Unexpected Remission From Extreme and Enduring Bulimia Nervosa With Repeated Ketamine Assisted Psychotherapy. Front. Psychiatry 2021, 12, 764112, doi:10.3389/fpsyt.2021.764112.

122. Walsh, Z.; Mollaahmetoglu, O.M.; Rootman, J.; Golsof, S.; Keeler, J.; Marsh, B.; Nutt, D.J.; Morgan, C.J.A. Ketamine for the Treatment of Mental Health and Substance Use Disorders: Comprehensive Systematic Review. BJPsych Open 2021, 8, e19, doi:10.1192/bjo.2021.1061.

123. Ito, Y.; Ichiyanagi, K. Post-Operative Pain Relief with Ketamine Infusion. Anaesthesia 1974, 29, 222-226, doi:10.1111/j.13652044.1974.tb00626.x.

124. Bion, J.F. Infusion Analgesia for Acute War Injuries. A Comparison of Pentazocine and Ketamine. Anaesthesia 1984, 39, 560564, doi:10.1111/j.1365-2044.1984.tb07362.x.

125. Holman, R.T.; Adams, C.E.; Nelson, R.A.; Grater, S.J.; Jaskiewicz, J.A.; Johnson, S.B.; Erdman, J.W. Patients with Anorexia Nervosa Demonstrate Deficiencies of Selected Essential Fatty Acids, Compensatory Changes in Nonessential Fatty Acids and Decreased Fluidity of Plasma Lipids. J. Nutr. 1995, 125, 901-907, doi:10.1093/jn/125.4.901.

126. Shih, P.B.; Yang, J.; Morisseau, C.; German, J.B.; Zeeland, A.A.S.-V.; Armando, A.M.; Quehenberger, O.; Bergen, A.W.; Magistretti, P.; Berrettini, W.; et al. Dysregulation of Soluble Epoxide Hydrolase and Lipidomic Profiles in Anorexia Nervosa. Mol. Psychiatry 2016, 21, 537-546, doi:10.1038/mp.2015.26.

127. Watson, H.J.; Yilmaz, Z.; Thornton, L.M.; Hübel, C.; Coleman, J.R.I.; Gaspar, H.A.; Bryois, J.; Hinney, A.; Leppä, V.M.; Mattheisen, M.; et al. Genome-Wide Association Study Identifies Eight Risk Loci and Implicates Metabo-Psychiatric Origins for Anorexia Nervosa. Nat. Genet. 2019, 51, 1207-1214, doi:10.1038/s41588-019-0439-2.

128. Diagnostic and Statistical Manual of Mental Disorders: DSM-5 $5^{T M}, 5 t h E d$; Diagnostic and statistical manual of mental disorders: DSM-5 ${ }^{\mathrm{TM}}$, 5th ed; American Psychiatric Publishing, Inc.: Arlington, VA, US, 2013; pp. xliv, 947; ISBN 978-0-89042-554-1. 
129. Newport, D.J.; Carpenter, L.L.; McDonald, W.M.; Potash, J.B.; Tohen, M.; Nemeroff, C.B.; APA Council of Research Task Force on Novel Biomarkers and Treatments Ketamine and Other NMDA Antagonists: Early Clinical Trials and Possible Mechanisms in Depression. Am. J. Psychiatry 2015, 172, 950-966, doi:10.1176/appi.ajp.2015.15040465.

130. Kishimoto, T.; Chawla, J.M.; Hagi, K.; Zarate, C.A.; Kane, J.M.; Bauer, M.; Correll, C.U. Single-Dose Infusion Ketamine and Non-Ketamine N-Methyl-d-Aspartate Receptor Antagonists for Unipolar and Bipolar Depression: A Meta-Analysis of Efficacy, Safety and Time Trajectories. Psychol. Med. 2016, 46, 1459-1472, doi:10.1017/S0033291716000064.

131. Harding, F.; Seynaeve, M.; Keeler, J.; Himmerich, H.; Treasure, J.; Kan, C. Perspectives on Psychedelic Treatment and Research in Eating Disorders: A Web-Based Questionnaire Study of People with Eating Disorders. J. Integr. Neurosci. 2021, 20, 551-560, doi:10.31083/j.jin2003059.

132. Renelli, M.; Fletcher, J.; Tupper, K.W.; Files, N.; Loizaga-Velder, A.; Lafrance, A. An Exploratory Study of Experiences with Conventional Eating Disorder Treatment and Ceremonial Ayahuasca for the Healing of Eating Disorders. Eat. Weight Disord. Stud. Anorex. Bulim. Obes. 2020, 25, 437-444, doi:10.1007/s40519-018-0619-6.

133. Spriggs, M.J.; Kettner, H.; Carhart-Harris, R.L. Positive Effects of Psychedelics on Depression and Wellbeing Scores in Individuals Reporting an Eating Disorder. Eat. Weight Disord. EWD 2021, 26, 1265-1270, doi:10.1007/s40519-020-01000-8.

134. Spriggs, M.J.; Douglass, H.M.; Park, R.J.; Read, T.; Danby, J.L.; de Magalhães, F.J.C.; Alderton, K.L.; Williams, T.M.; Blemings, A.; Lafrance, A.; et al. Study Protocol for "Psilocybin as a Treatment for Anorexia Nervosa: A Pilot Study." Front. Psychiatry 2021, 12, 735523, doi:10.3389/fpsyt.2021.735523.

135. Ernst, J.; Böker, H.; Hättenschwiler, J.; Schüpbach, D.; Northoff, G.; Seifritz, E.; Grimm, S. The Association of Interoceptive Awareness and Alexithymia with Neurotransmitter Concentrations in Insula and Anterior Cingulate. Soc. Cogn. Affect. Neurosci. 2014, 9, 857-863, doi:10.1093/scan/nst058.

136. Nakazato, M.; Hashimoto, K.; Schmidt, U.; Tchanturia, K.; Campbell, I.C.; Collier, D.A.; Iyo, M.; Treasure, J. Serum Glutamine, Set-Shifting Ability and Anorexia Nervosa. Ann. Gen. Psychiatry 2010, 9, 29, doi:10.1186/1744-859X-9-29.

137. Sleigh, J.; Harvey, M.; Voss, L.; Denny, B. Ketamine - More Mechanisms of Action than Just NMDA Blockade. Trends Anaesth. Crit. Care 2014, 4, 76-81, doi:10.1016/j.tacc.2014.03.002.

138. Strasburger, S.E.; Bhimani, P.M.; Kaabe, J.H.; Krysiak, J.T.; Nanchanatt, D.L.; Nguyen, T.N.; Pough, K.A.; Prince, T.A.; Ramsey, N.S.; Savsani, K.H.; et al. What Is the Mechanism of Ketamine's Rapid-Onset Antidepressant Effect? A Concise Overview of the Surprisingly Large Number of Possibilities. J. Clin. Pharm. Ther. 2017, 42, 147-154, doi:10.1111/jcpt.12497.

139. Zanos, P.; Gould, T.D. Mechanisms of Ketamine Action as an Antidepressant. Mol. Psychiatry 2018, 23, 801-811, doi:10.1038/mp.2017.255.

140. Matveychuk, D.; Thomas, R.K.; Swainson, J.; Khullar, A.; MacKay, M.-A.; Baker, G.B.; Dursun, S.M. Ketamine as an Antidepressant: Overview of Its Mechanisms of Action and Potential Predictive Biomarkers. Ther. Adv. Psychopharmacol. 2020, 10, 2045125320916657, doi:10.1177/2045125320916657.

141. Wilkinson, S.T.; Ballard, E.D.; Bloch, M.H.; Mathew, S.J.; Murrough, J.W.; Feder, A.; Sos, P.; Wang, G.; Zarate, C.A.; Sanacora, G. The Effect of a Single Dose of Intravenous Ketamine on Suicidal Ideation: A Systematic Review and Individual Participant Data Meta-Analysis. Am. J. Psychiatry 2018, 175, 150-158, doi:10.1176/appi.ajp.2017.17040472.

142. Krystal, J.H.; Abdallah, C.G.; Sanacora, G.; Charney, D.S.; Duman, R.S. Ketamine: A Paradigm Shift for Depression Research and Treatment. Neuron 2019, 101, 774-778, doi:10.1016/j.neuron.2019.02.005.

143. McMullen, E.P.; Lee, Y.; Lipsitz, O.; Lui, L.M.W.; Vinberg, M.; Ho, R.; Rodrigues, N.B.; Rosenblat, J.D.; Cao, B.; Gill, H.; et al. Strategies to Prolong Ketamine's Efficacy in Adults with Treatment-Resistant Depression. Adv. Ther. 2021, 38, 2795-2820, doi:10.1007/s12325-021-01732-8.

144. Aroke, E.N.; Crawford, S.L.; Dungan, J.R. Pharmacogenetics of Ketamine-Induced Emergence Phenomena: A Pilot Study. Nurs. Res. 2017, 66, 105-114, doi:10.1097/NNR.0000000000000197.

145. Hasler, G. Toward Specific Ways to Combine Ketamine and Psychotherapy in Treating Depression. CNS Spectr. 2020, 25, 445447, doi:10.1017/S1092852919001007.

146. Dore, J.; Turnipseed, B.; Dwyer, S.; Turnipseed, A.; Andries, J.; Ascani, G.; Monnette, C.; Huidekoper, A.; Strauss, N.; Wolfson, P. Ketamine Assisted Psychotherapy (KAP): Patient Demographics, Clinical Data and Outcomes in Three Large Practices Administering Ketamine with Psychotherapy. J. Psychoactive Drugs 2019, 51, 189-198, doi:10.1080/02791072.2019.1587556.

147. Wilkinson, S.T.; Wright, D.; Fasula, M.K.; Fenton, L.; Griepp, M.; Ostroff, R.B.; Sanacora, G. Cognitive Behavior Therapy May Sustain Antidepressant Effects of Intravenous Ketamine in Treatment-Resistant Depression. Psychother. Psychosom. 2017, 86, 162-167, doi:10.1159/000457960.

148. Krupitsky, E.M.; Burakov, A.M.; Romanova, T.N.; Dunaevsky, I.V.; Grinenko, A.Y. Ketamine Assisted Psychotherapy (KPT) of Heroin Addiction: Immediate Effects and Six Months Followup. MAPS Bull. 2001, 9, 21-26.

149. Halstead, M.; Reed, S.; Krause, R.; Williams, M.T. Ketamine-Assisted Psychotherapy for PTSD Related to Racial Discrimination. Clin. Case Stud. 2021, 20, 310-330, doi:10.1177/1534650121990894.

150. Davis, A.K.; Mangini, P.; Xin, Y. Ketamine-Assisted Psychotherapy for Trauma-Exposed Patients in an Outpatient Setting: A Clinical Chart Review Study. J. Psychedelic Stud. 2021, 5, 94-102, doi:10.1556/2054.2021.00179. 